\title{
Creating knowledge: the power and logic of articulation
}

\section{Lars Håkanson}

The current interest in the tacit aspects of knowledge has diverted attention from the economic significance of its converse, explicit or articulated knowledge, and, by implication, the importance of articulation - the process through which tacit skills and knowledge are made explicit-and codification-the process of rendering articulated knowledge in fixed, standardized and easily replicable form. In partial alignment with the literature on "distributed cognition" the article outlines a general model of articulation as a process involving the interplay of three elements: "theory," "codes," and "tools" in communities ranging in size from small groups to entire industries. The costs and benefits of articulation are discussed, drawing attention to how these may be affected by institutional and organizational design.

The current, and justified, fascination with the tacit component of knowledge ... must not cloud the fact that organizations to a large extent are 'articulation machines,' built around codified practices and deriving some of their competitive advantages from clever, unique articulation. In fact, much of industrialization seems to have entailed exactly the progressive articulation of craftsman-like skills, difficult but not impossible to codify. (Hedlund, 1994: 76)

\section{Introduction}

In a whole range of areas, including strategy, organization, knowledge management, science policy and others, "tacit knowledge" has become a fashionable brand of snake oil, invoked to explain a wide and disparate range of phenomena, both merely hypothetical ones and ones actually observed. However, in reviewing the literature the reader is struck by the extreme conceptual ambiguity, theoretical confusion and lack of agreement characteristic of the way the term is being used. Moreover, the present interest in the tacit aspects of knowledge has tended to divert attention from the economically obvious significance of its converse, explicit or articulated knowledge, and, by implication, the importance of articulation, the process through 
which tacit skills and knowledge are made explicit. Heeding Gunnar Hedlund's advice in the epigraph, this article is an attempt to redress this imbalance.

The prevailing focus on the tacit aspects of knowledge has certainly enriched our understanding of their significance for a range of issues in science policy, management, and strategy. But it has been associated with a tendency to downplay the importance of explicit knowledge and with a near total neglect of the significance of articulation and codification for the advancement of knowledge. It is now time, I shall argue, that we rediscover the importance of articulation and redirect research attention to the determinants and consequences of explication and codification, i.e., the power and logic of articulation, and to the question of how the design and organization of these processes affect their costs and benefits.

Explication and codification of tacit knowledge are not only intrinsic to the creation of new knowledge, they are also prerequisites for its efficient transfer over both time and space and, therefore, for both its cumulative growth and its diffusion. Moreover, articulation and creation of knowledge have fundamental effects on the power relationships within and between firms, as well as within and between societies. How, why and by whom are the decisions made whether a particular articulation is to be pursued rather than another? What are the consequences of these choices? The overall aim of this article is to provide a model of the articulation process that can be instrumental in formulating a research agenda addressing these issues.

The article is organized as follows: The following section deals with the nature of tacit knowledge. Given the lack of agreement in the literature, its aim is to formulate a logical and consistent set of definitions of the central concepts involved: the distinction between "tacit" and "explicit" knowledge and the nature of "articulation"- the process through which the former can be transformed into the latter. The argument suggests that-with a few important exceptions-the knowledge informing most economically relevant skills are, at least potentially, articulable.

The third section outlines a model of the articulation process, "the articulation circle," that frames articulation as a social process of knowledge creation carried on within communities of practitioners, based on the interplay of three elements: "theory," "code," and "tools." I discuss the nature of these components and their interplay, drawing on historical and present day examples. The purpose is to provide a language and a conceptual model to aid the description and analysis of knowledge creating processes.

The fourth section focuses on the benefits of articulation and the conditions under which communities are likely to incur the costs and effort that it requires. Three major classes of benefit are identified. First, articulation favors innovation and knowledge creation. Second, it promotes the division of labor and therefore advantages of specialization, economies of scale, etc. Third, articulation is associated with improved capabilities for replication and control, important for quality control, 
technology transfer, etc. However, as the section also points out, the benefits of articulation and codification are not unproblematic and their distribution often has important social and political implications.

The concluding section outlines some implication of the proposed perspective for the analysis of knowledge creating processes involving distributed learning processes at the level of small work groups, in professional communities, as well as in firms and other organizations. The workings of the model at the level of an industry are illustrated by reference to the development of the wind turbine industries in the United States and Denmark, drawing on a recent analysis by Karnøe (1999) and Garud and Karnøe (2003). It highlights how institutional and socio-technical conditions affect the temporal, geographical and organizational structure of the articulation process. When, where and by whom the development of new theory, new codes, and new artifacts are undertaken, but also the mode of interaction between these activities vitally affect the direction and outcome of the knowledge generation process.

\section{The nature of tacit knowledge}

\subsection{The concept of "tacit knowledge" in current literature}

In the two decades since Nelson and Winter (1982) brought Polanyi's notion of "tacit knowledge" to the attention of economists, the concept has-as Cowan et al. point out-come to enjoy a "wonderful new career":

... [A] notion that took its origins in the psychology of visual perception and human motor skills has been wonderfully transmuted, first from an efficient mode of mental storage of knowledge into a putative epistemological category ... from there into a phenomenon of inarticulable inter-organizational relationships and finally to one of the keys to corporate, and perhaps also national, competitive advantage! (Cowan et al., 2000: 223)

In the process, the nuanced treatment in the original discussion (Nelson and Winter, 1982, Chapter 4) has been lost—in large part because the profession has failed to seek consensus as to the terminology and its conceptual basis:

"Tacit knowledge," it is generally agreed, is revealed through application and cannot be written down. Regarding the possibility of transforming-articulatingtacit knowledge into explicit knowledge, there is no such convergence of views. According to Grant and Baden-Fuller (1995: 18), for example, "tacit knowledge" is "by definition" not capable of articulation. In a similar vein, Reed and DeFillippi (1990: 89) define "tacitness" as "the implicit and uncodifiable accumulation of skills that result from learning by doing." (Italics added.) At the other extreme, 
Schulz and Jobe (2001: 142) assume that "all tacit knowledge can potentially be translated into explicit knowledge." According to this line of reasoning, "tacit knowledge" is knowledge that is "difficult" to articulate, but the conditions under which this is possible and desirable remain obscure:

Tacit knowledge is knowledge that is not codified. If it could be codified, then it would no longer be tacit knowledge; it would have become explicit knowledge. It is possible to convert some tacit knowledge into explicit knowledge... but much tacit knowledge is difficult, if not impossible, to codify and can never be made explicit. (Berman et al., 2002: 14)

Wagner and Sternberg (1985) avoid the issue altogether: "By tacit, we refer to knowledge that usually is not openly expressed or stated... [W] e do not mean to imply that this knowledge is inaccessible to conscious awareness, unspeakable, or unteachable, but merely that it is not taught directly..." (Wagner and Sternberg, 1985: 438f.).

Taking a slightly different approach, Grant (1996a: 111) identifies "knowing how with tacit knowledge and knowledge about facts and theories with explicit knowledge." He does not seem to exclude the possibility of articulation: "If tacit knowledge cannot be codified... its transfer between people is slow, costly and uncertain." (Italics added.) This suggests that tacit "knowing how" can be codified into explicit "knowledge about facts and theory" but the implications of such a transformation are unclear. Can knowledge be tacit and explicit at the same time or does "knowing how" disappear in the process?

In fact, the curious idea that articulation "destroys" knowledge is not uncommon in the literature. Soo et al. (2002: 131) provide one of its more extreme expressions: "True knowledge," they claim, is "by definition" non-codified. "As soon as it becomes codified and transmittable it ceases to be knowledge and becomes data."

Although not so specific about the precise mechanisms, Kreiner (2002) seems to have something similar in mind:

To transform [through articulation and codification] tacit knowledge into company property is a legitimate managerial goal. It makes good sense to find ways of taking care of the knowledge that leaves the company at night. But simply put, the less knowledge that leaves in the evening, the less knowledge returns in the morning. (Kreiner, 2002: 21)

The examples of "tacit knowledge" given in the literature typically refer to simple motor skills, such as swimming, bicycle riding, or tennis-far removed from the type of skills likely to provide competitive advantage to firms. More economically relevant examples are rare, although Subramaniam and Venkatraman (2001: 362), for example, discuss as a "tacit insight" the discovery that US consumers tend to snack 
while using the telephone. (Detecting the intriguing "tacit habit" of soiling cordless phones is said to have offered Sony a "unique innovation opportunity.")

In spite of their various interpretations as to its precise nature, most writers concur that "tacit knowledge" is an important source of competitive advantage. The notion is based on the belief that tacit knowledge is difficult to imitate and has become popular because of its neat fit into the prevailing "resourced based view" of strategy. Following Winter (1987), the idea is often combined with its converse, i.e., explicit knowledge is by nature easily imitated and can therefore only provide momentary advantage. The conclusion commonly made is that it is easier to appropriate the returns to tacit than to codified knowledge.

Since "tacitness" is typically associated with poorly understood skills, this train of thought sometimes comes perilously close to identifying lack of knowledge as a means to sustainable competitive advantage. Reed and DeFillippi (1990: 91) note, for example, that "... tacitness generates ambiguity through the skilled operator's own level of unawareness of the actions that he or she undertakes." Normatively, they suggest (p. 98), “... reinvestment in ambiguity should be aimed at competencies on which advantage is based and from which ambiguity is derived."

\subsection{A taxonomy of knowledge}

As noted by Hedlund and Zander (1993: 12), the root of the conceptual confusion is that “"...tacitness' is defined as a negation of something in itself undefined. It is posed as that which is not articulated, articulable, codified, or codifiable. As in all cases of negative definitions, the risk is that a heterogeneous assemblage of aspects is subsumed under one label."

The confusion has undoubtedly been added to also by the curious inability of the English language to easily distinguish between "substantial knowledge"- "know that" and "know-why" (Wissen, savoir-connaitre)—and "procedural knowledge"know-how (Können, savoir-faire). ${ }^{1}$ Although the distinction is sometimes emphasized, the nature of the simple relation between the two is generally overlooked or concealed by ill-chosen metaphors. In consequence, the fact that skills and substantive knowledge have different characteristics and economic implications is often obscured: Substantive knowledge serves to inform the exercise of a skill: "I can add these numbers because I know (and understand) a few simple rules of arithmetic." "I can find my way to Piccadilly Circus because I know the map of London (and understand the codes and conventions necessary to interpret maps)." Knowledge obtains economic significance through application in economic activity, i.e., the exercise of a skill.

\footnotetext{
${ }^{1}$ For Polanyi, whose main interest is a critique of positivist theory of science, the difference is not very significant: "These two aspects of knowing have similar structure and neither is ever present without the other...I shall always speak of 'knowing' therefore, to cover both practical and theoretical knowledge" (Polanyi, 1966: 7).
} 


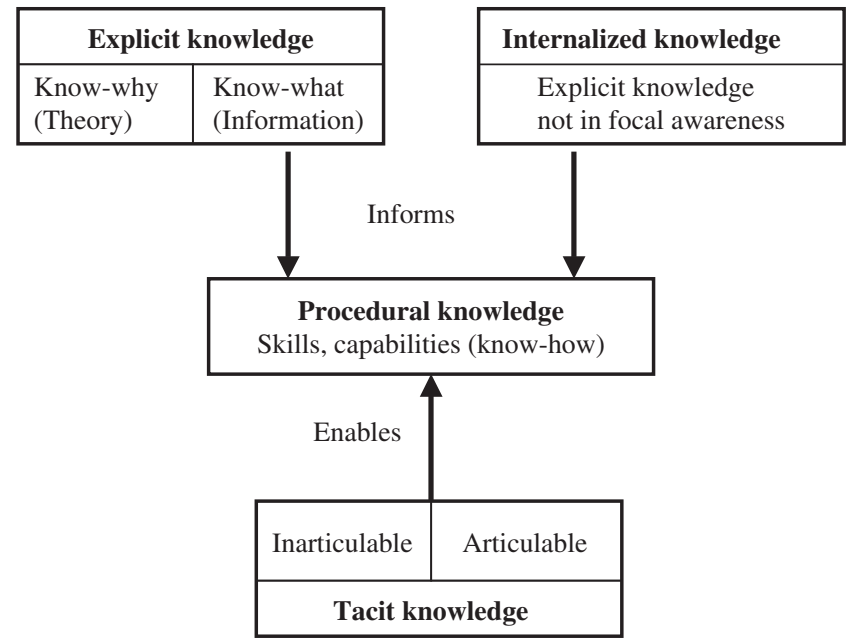

Figure 1 Skills, tacit and explicit knowledge.

This is not to say that all skills are reducible to a set of rules and "knowings-that" (Ryle, 1945/1946). Polanyi's notion of "tacit knowledge" is based on the observation that, at times, skills can be exercised without the performer being able to easily and fully account for their cognitive basis. (I can detect business opportunities that others do not see, but I cannot explain why.) This unarticulated cognitive foundation cannot be directly observed, but may, he claims, be inferred when "... the aim of a skilful performance is achieved by the observance of a set of rules which are not known as such by the person observing them" (Polanyi, 1962: 49, italics in the original).

Accepting Polanyi's semantics, the "set of rules" that inform the exercise of a skill can be wholly, partly or not at all accessible to consciousness. Conscious rules, and associated causal beliefs, can be more or well articulated. Skills vary in (i) the degree to which their exercise relies on articulable rules, (ii) the degree to which such articulable rules have, in fact, been articulated, and (iii) the cost, effort, and means that would be required to increase the degree of articulation.

In line with this argument, three types of cognitive knowledge (as opposed to procedural skills) can be distinguished (Cowan et al., 2000). In the following, "explicit knowledge" refers to articulated rules and beliefs, which are shared and recognized as actionable knowledge within a community. "Internalized knowledge" denotes explicit knowledge of which the acting agent is not focally aware. "Tacit knowledge," finally, refers to rules and beliefs that have not been articulated, but whose existence is inferred from the observance of skilful performance (Figure 1).

\footnotetext{
${ }^{2}$ The knowledge to which I refer is thus socially constructed and context dependent. The relevant context is the community where it resides and whose criteria determine what evidence is required for a belief to be recognized as actionable knowledge (cf. Brown and Duguid, 1998: 99).
} 
The three types of knowledge are complementary and-to varying degrees-most economically relevant capabilities draw on all three. ${ }^{3}$

\subsubsection{Explicit knowledge}

Explicit knowledge is conventionally divided into "know-what," i.e., information, knowledge of facts, etc., and "know-why," knowledge of principles, theory, causalities and the like. It is with the aid of the latter that we interpret or "give meaning to" the former; data without reference to cognitive schemata are meaningless. A further important class of explicit knowledge is knowledge of codes and symbols. Together with knowledge of associated theory, mastery of codes is an important determinant of an agent's "absorptive capacity" (Cohen and Levinthal, 1990). ${ }^{4}$

A very large portion of the time spent in formal education programs is devoted to the teaching and (in smaller portion) learning explicit knowledge. In modern societies, professional work is unthinkable without substantial knowledge, but the same is true for many everyday activities also.

\subsubsection{Internalized knowledge}

Over time, both in professional and everyday life, much of the explicit knowledge informing our activities become (with practice and habit) so "natural" or "commonplace" that they escape conscious attention. Such "internalized knowledge" forms a second category of knowledge (Nonaka, 1991; Hedlund and Nonaka, 1993; Hedlund, 1994; Nonaka and Takeuchi, 1995; Nightingale, 2003: 156ff.). Internalization economizes on limited cognitive, perceptual, and coordinative resources, in the process transforming deliberate behavior into routines (March and Simon, 1958; Hedlund, 1994). Internalized knowledge informs an agent's capabilities without being in her focal awareness (Polanyi, 1962).

Internalization is often a prerequisite for proficiency (Sternberg and Horvath, 1999). It sometimes takes considerable time to accomplish and may therefore have scarcity value. But in many other instances-driving an automobile, for examplethe time and effort required can be quite modest. Although the skill of pizza makers to hand toss pizza dough increases with experience (Argote, 1999: 69), the economic significance of this fact is probably limited.

\footnotetext{
${ }^{3}$ As Reber (1997: 145) emphasizes, “... the implicit-explicit distinction is not between two isolated cognitive modules but between two poles on a continuum. At one pole are processes that are palpably conscious; at the other there are those that are manifestly unconscious."

${ }^{4}$ Without such mastery, explication can in fact be detrimental to performance. In an interesting experiment, Melcher and Schooler (1996) examined how the attempt to verbally describe the flavor of a wine affected the ability to subsequently identify it from among three samples. For non-wine drinkers, with little or no verbal and perceptual expertise in wine tasting, verbalization was detrimental to wine recognition - a phenomenon known as "verbal overshadowing" (Dodson et al., 1997). However, participants with previous perceptual expertise and some knowledge of the relevant vocabulary and its conventions did not experience the effect.
} 
Internalization makes explicit rules progressively irrelevant. This is accompanied by changes in the pattern of neural activity producing a "gain in speed and precision, but a loss in context-sensitivity, accessibility, and flexibility" (Tononi and Edelman, 1998: 1847, in Nightingale, 2003: 158). Internalized knowledge thus shares many of the characteristics of implicitly acquired, unarticulated "tacit knowledge," and to an outside observer the difference may be difficult to detect (Cowan et al., 2000: 232). ${ }^{5}$

Internalizing knowledge does not alter its degree of articulation. The instructions of an operating manual do not become less explicit just because with practice they tend to become internalized by the operator. If prompted to do so, a person drawing on such knowledge is able, oftentimes with ease, sometimes with more difficulty, to explicate the rules underlying his/her performance.

\subsubsection{Inarticulable tacit knowledge}

The third category, "tacit knowledge," includes, on the one hand, "truly tacit," i.e., "inarticulable knowledge"; and, on the other, "articulable tacit knowledge"knowledge that could be but has not (yet) been articulated (Cowan et al., 2000). In the present context, this is clearly the most interesting category and it will provide the focus for most of the following discussion. First, however, a few words should be spent on "truly tacit" knowledge, a subject on which the inherited literature displays much confusion and widely divergent opinions.

Although this is rarely spelled out, in management literature "tacit knowledge" is usually taken to apply to acquired skills_-it does not include "natural" human faculties, such as sense perception and muscular control, nor most "naturally" acquired skills, such as walking upright without losing balance or mastering basic rules of grammar. Such skills are typically acquired through implicit learning, relying on phylogenetically ancient structures, independent of and often inaccessible to consciousness (Reber, 1989, 1997; Nightingale, 2003). ${ }^{6}$

It is striking, however, that many of the examples of "tacit knowledge" offered by Polanyi (and the ones most often quoted), such as the motor skills of riding a bicycle or swimming, refer to capabilities closely relying on inherited, neurologically determined faculties. Their successful performance requires speed and simultaneity

\footnotetext{
${ }^{5}$ The human ability to perform a task without being focally aware of the underlying knowledge seems to be the basis for the curious idea that through "internalization" (Nonaka, 1991; Hedlund and Nonaka, 1993; Hedlund, 1994; Nonaka and Takeuchi, 1995) or "absorption" (Boisot, 1995; Boisot et al., 1997) explicit knowledge can be reconverted into tacit knowledge.

${ }^{6}$ As emphasized by Reber (1989, 1991, 1997), the assumed evolutionary primacy of implicit, unconscious learning has several important implications. Implicit systems can be expected to be more robust to psychiatric or neurological insult and to show less individual variability than do conscious cognitive processes associated with, decision-making, problem-solving, recognition, and (conscious) memory recall, etc. Although conclusive evidence is still lacking, it appears, for example, that individuals' performance of explicit tasks vary more and are stronger correlated with differences in IQ than do implicit skills that seem to be unrelated to traditional measures of cognitive capability.
} 
of information processing. The learner must work out the detailed muscular coordination by himself, perhaps (like an apprentice) with the help and encouragement of someone mastering the art (Hedlund and Zander, 1993: 10). These sorts of skills are "inarticulable" in ways similar to natural faculties. Polanyi's explication of bicycle riding, for example, explains the relevant physical principles, but it is not very helpful for anyone wishing to master the art:

The rule observed by the cyclist is this. When he starts falling to the right he turns the handlebars to the right, so that the course of the bicycle is deflected along a curve towards the right. This results in a centrifugal force pushing the cyclist to the left and offsets the centrifugal force dragging him down to the right. This manæuvre presently throws the cyclist out of balance to the left, which he counteracts by turning the handlebars to the left; and so he continues to keep himself in balance by winding along a series of appropriate curvatures. A simple analysis shows that for a given angle of unbalance the curvature of each winding is inversely proportional to the square of the speed as which the cyclist is proceeding. (Polanyi, 1962: 49)

Polanyi's explication parallels the optical and neurological principles of eyesight articulated by the medical profession. Although in many ways useful, they are as irrelevant to the capability of seeing as knowledge of inertial forces and Newton's first law to the art of bicycling.

Hearing, sight, and other natural human faculties are not accessible to consciousness and cannot be articulated in ways that are instrumental to their exercise. ${ }^{7}$ Their analysis, although significant in areas such as neurology, linguistics, and philosophy, fall largely outside the realm of economic enquiry. This seems to be the line of reasoning underlying the claim by Cowan et al. (2000: 230), that inarticulable knowledge is "not very interesting for the social sciences." However, this statement is clearly too rash. Theoretical understanding of inarticulable human faculties can have considerable economic significance. A better scientific comprehension of the physiology and psychology of hearing, for example, is clearly relevant to the development of commercially viable speech recognition software. ${ }^{8}$

\footnotetext{
${ }^{7}$ As Nightingale (2003: 156) puts it: “... no amount of money will allow us to articulate how the vestibular ocular reflex keeps our visions stable as we move."

${ }^{8}$ In fact, the economic benefits of a better understanding of perceptual skills and other innate human faculties and the processes by which such understanding is obtained in many ways parallel those associated with the articulation of acquired tacit skills. A small Danish start-up company, SoundFacts ApS, has developed and is now commercializing software that successfully mimics the capacity of the human ear to detect transients, i.e., small changes in the energy of sound, such as those associated with clicks, rattles, and hiss. Among the many interesting applications of this new method to detect and new code to describe "squeak and rattle" are the replacement of the "golden ears" today used for quality control in many industries. The potential of the technology parallels one-to-one the benefits of articulation discussed subsequently.
} 
Moreover, there are at least two (and possibly more) important types of economically significant skills that are based on largely inarticulable, "truly tacit" knowledge: social skills and creativity.

Social skills. The basis for social skills-here taken to include a wide range of capabilities such as management and leadership skills, ability to work in groups, motivate others, negotiating, selling, etc.-is typically formed during adolescence and early childhood. Later in life, experience can provide tacit knowledge regarding, for example, how to manage oneself, manage others, or manage ones career (Wagner and Sternberg, 1985). Such knowledge is hardly ever acquired through formal training. Educational programs, courses, and seminars can only with marginal effect (if at all) hope to develop and strengthen social skills (Baldwin and Ford, 1988). To the extent that they do, they are typically based on methods of instruction emphasizing role-play, practical exercises and emulating the interaction between master and apprentice (Vermeulen, 2002). Explication is typically of little avail. Etiquette can perhaps be learnt through the study of appropriate books; the skills associated with charm, charisma and a winning personality cannot be acquired in this way.

Creativity. Creativity, the ability to frame problems and to conceive of and do new things, is a further inarticulable skill (Leonard and Sensiper, 1998). This applies equally to scientific discovery, the engineer's conception of a new design or the entrepreneur's identification of a new business opportunity as it does to the creation of an original work of art. Interestingly, articulation of tacit knowledge is often itself a creative activity, based at least partly on skills that are themselves inarticulable.

In science, there is a fundamental difference between the logic of discovery and the logic of demonstration. Articulation and codification constitute the very essence of the latter; discovery, at least in the true sense of finding something "totally" new, cannot be codified. The skill of discovery, like other creative talent, cannot be prescribed and codified. This is not to preclude, of course, that given the right circumstances, it can, as can other types of tacit knowledge, be passed on from master to apprentice (Ravetz, 1971/1996).

The argument can also be phrased differently. In all articulation, some of the perceptual texture and "richness" of the original knowledge is inevitably lost (Boisot and Child, 1988: 508). Sometimes, this loss has serious consequences. ${ }^{9}$ Truly creative skills, such as those of art, music, or cooking, can only be codified with extreme loss of quality. This is why the "music" produced by electric pianos is so far from the real thing as are the hamburgers of McDonald's from a visit to Maxim's.

\footnotetext{
${ }^{9}$ As elaborated subsequently, providing focus on the essential (and ignoring the rest) is, in fact, usually one of the benefits of articulation. Weick (1999: 42) notes that, “. . in order for people to make sense of something, they often have to ignore much that others might notice. Reality is not so much discovered as buried in the interest of sensemaking. To make sense is to focus on a limited set of cues and to elaborate those cues into a plausible, pragmatic, momentarily useful guide for actions..."
} 
Like all tacit knowledge, creative skills only develop slowly and with difficulty. The art of composing music has certainly developed since the 18th century, but Mozart's is as distinctive today as in his own lifetime. And it appears improbable that today's chefs are much superior to the ones preparing the banquets for the imperial court of his time.

\subsubsection{Articulable tacit knowledge}

At any moment in time, the boundaries between the inarticulable and the articulable are determined by the availability of appropriate codes. It is therefore difficult to very precisely differentiate between skills that cannot be articulated, because their nature precludes it, and those that cannot be so, because appropriate codes are not (yet) available. However, with the exceptions noted earlier, it seems that most tacit skills of economic interest are at least potentially articulable. These include a large range of experience-based knowledge, informing, for example, engineering design and many manufacturing activities. Explication of such knowledge has profound economic, social, and political effects. The conditions that induce articulation, the mechanisms through which it takes place and its effects are the subjects of the remainder of this article.

\subsubsection{Articulation and codification}

In much current literature, "articulation" and "codification" are often synonymously used to denote the process of expressing tacit knowledge into some socially shared code or symbolic representation-in the simplest case, ordinary natural language. However, it is useful to maintain a distinction between "articulation" and "codification." While recognizing that the definitions are somewhat arbitrary and that other writers may prefer other usages, following Zollo and Winter (2002), I propose to let "codification" denote the expression of knowledge in a standardized, fixed form. ${ }^{10}$ In this usage, "codification" refers to the creation of messages but not, as

\footnotetext{
${ }^{10}$ Not coincidentally, Eisenstein (1983) regards "standardization," "dissemination," and "fixity" as the distinguishing characteristics of modern "print culture," based on the invention of moveable type and the possibility to precisely repeat word symbols in exact order. These are significant characteristics of print technology, regardless of the authority, truthfulness, or authenticity of that which is printed (Johns, 1998). As Ivins point out, a similar revolution had occurred nearly a hundred years earlier with the discovery of means to print exactly repeatable pictorial statements: "The exact repetition of pictorial statements has had incalculable effects upon knowledge and thought, upon science and technology, of every kind" (Ivins, 1953/1969: 3). Of course, "standardization" and "fixity" are not absolute criteria but relative and context dependent. The borderline is sometimes fluent. Engineering designs, for example, are often first articulated in the form of "thinking sketches" (Ferguson, 1992/2001: 96f.) and it may be difficult to precisely determine where on the way to the final engineering drawing "codification" has taken place. Digital documents, such as web pages have less fixity than those printed on paper (Brown and Duguid, 2000).
} 
is sometimes the case, to the creation of codes in which messages can be composed. (The distinction is central to the argument elaborated subsequently.)

Adopting this semantic convention, "codification" presupposes "articulation" but knowledge can be "articulated" without being "codified" and not all uncodified knowledge is tacit (Zollo and Winter, 2002). The "war stories" told by the service technicians studied by Orr (1996) articulate, but do not codify (as do the company manuals) their experiences of especially difficult repairs. Although obviously important for their work and the development of their practice, the knowledge that the stories embody runs an obvious danger of being corrupted the more often they are retold. The company manuals, although often less useful, are not exposed to this risk.

The distinction is important both for theory and for managerial practice. It is through codification that knowledge becomes embedded in transferable artifacts that can be transferred over long distances, often at minimal cost. Communication of articulated but uncodified knowledge can, like transmission of tacit knowledge, be accomplished only by means of some type of personal contact.

Articulation and codification are sometimes simultaneous, but since codification requires additional time and resources this is not always the case. One of the classic problems in the implementation of "knowledge management" systems is how to create incentives for employees to spend the time and energy necessary to codify and document their knowledge in ways that allow it to be stored and accessed (Soo et al., 2002: 141). Moreover, codifying their knowledge and making it accessible to other people entails a loss of control of it that employees may be reluctant to accept. In consequence, articulated knowledge is sometimes never codified-or only incompletely so-and there may be considerable time lags between articulation and codification. In technology transfer, differences between "actual" and codified knowledge can cause serious conundrum. This is often the case, for example, when blueprints have not been updated to reflect alterations to machinery made in response to experiences of actual operating conditions.

\section{The articulation circle}

Articulation does not take place in a void. It is always embedded in specific practice, the needs, goals and values of which determine its direction and form. The precise mode of articulation-both the means and symbols and the meaning attached to them-is therefore context dependent and vary between organizations and communities depending of the practices they pursue (Sanchez, 1997). Defining the context delineates the community where knowledge resides.

As a rule, there is no reason to presuppose that all people in the world possess the knowledge needed to interpret the codes properly. 
This means that what is codified for one person or group may be tacit for another and an utterly impenetrable mystery for a third. Thus context temporal, spatial, cultural and social - becomes an important consideration in any discussion of codified knowledge. (Cowan et al., 2000: 225)

Whether based on the highly tacit knowledge of traditional crafts or on the explicit theories that underlie activities in so-called "science-based" industries, all practice encompasses three fundamental elements: cognitive frames ("theory"), coding schemes and other symbolic means of expression ("code"), and the technology embedded in physical artifacts ("tools").

These three basic elements of practice are emphasized already in Vitruvius' "De Architectura" of the first century B.C.- - one of the earliest known examples of purposeful articulation and codification of knowledge-in a famous passage enumerating the skills required of an accomplished architect:

An architect... must have a knowledge of drawing [code] so that he can readily make sketches to show the appearance of the work which he proposes. Geometry [theory], also, is of much assistance in architecture, and in particular it teaches us the use of the rule and compasses [tools], by which especially we acquire readiness in making plans for buildings in their grounds, and rightly apply the square, the level, and the plummet. By means of optics, again, the light in buildings can be drawn from fixed quarters of the sky. It is true that it is by arithmetic that the total cost of buildings is calculated and measurements are computed, but difficult questions involving symmetry are solved by means of geometrical theories and methods. (Morgan, 1914: 6)

Some codes, some theories and the use of some tools are generally learnt as part of a typical primary school curriculum, for example the rules and conventions of writing the local language and the skills of using a pencil. But many require more advanced general education and yet others are learnt in specialized training programs or in actual practice. It is in the interplay and interaction between these elements that articulation and codification of knowledge is possible (Figure 2).

The primary aim of articulation is typically to develop more explicit theory, but the process typically requires a transformation of relevant codes and tools as well. Conversely, the emergence of new tools or the development of new and more powerful codes often provides the very impetus for articulation.

A striking illustration is offered by McGee (1999), in his discussion of the impact of measured multiview plans (the "code") on shipbuilding through the development of a coherent body of knowledge (the "theory") regarding the relationship between 


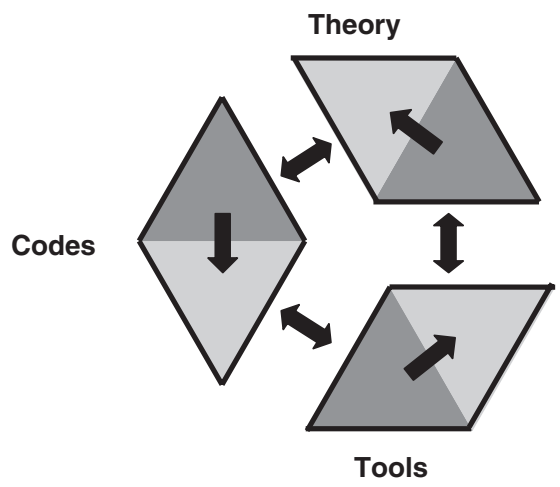

Figure 2 The articulation circle.

various aspects of a ship's physical characteristics (the "tool"), hull shape, displacement, weight, etc., and its behavior at sea:

The most important [point]: drawings first, then science. Without the use of measured plans there could be nothing to quantify and so no possible application of mathematical physical theory whatsoever. The second point is that without the use of measured plans to achieve accuracy in construction there could be no point in applying scientific theory, since there could be no point in calculating the behavior of a 'paper' ship if the real ship was going to be built (and therefore behave) differently especially not when small variations in shape are known to produce large changes in behavior. The third point is that what cannot get into the plans cannot get into the ship. This is important because it gives us definite criteria for judging the utility of physical theory. (McGee, 1999: 230)

Articulation implies knowledge creation-it allows tasks to be accomplished that could not previously be accomplished or not accomplished so well. By definition, articulation leads to an increase in the amount of explicit knowledge available to the community in question. However, this does not imply that the degree of tacitness of its overall knowledge base necessarily declines. The application of new, more explicit theory, tools, and codes exposes individuals and groups also to new experiential learning opportunities. Much of this learning is implicit and leads to the creation also of new forms of tacit knowledge (Resnick et al., 1991; Boisot, 1995). ${ }^{11}$

\footnotetext{
${ }^{11}$ Cambrosio and Keating (1988) describe in fascinating detail how, in the mid-1980s, the exploitation of hybridoma technology, one of the foundations of the biotechnology industry, required a range of new artisanal skills that its practitioners acquired in craftsmanlike apprenticeship. Similar accounts are provided by Zuboff (1988, in Henderson, 1999: 57) on the reading of computerized instruments in paper pulp production and Goodwin (1997) on the construction of a scientific instrument in a geochemistry lab.
} 
While knowledge creation is typically driven by the transformation of the tacit to the explicit, it usually entails a growth in both forms of knowledge. ${ }^{12}$

\subsection{Theory}

All practice requires some assumptions or understanding of causal means-end relationships. This understanding can be highly tacit, as in the habits, conventions, and traditions that form "team mental models" (Mohammed and Dumville, 2001), "organizational cultures" (Schein, 1985), "dominant logics" (Prahalad and Bettis, 1986), or "industry recipes" (Spender, 1989), and in those guiding the work of an accomplished craftsman, or they can be explicit, as in the case of tested scientific hypotheses. Articulation depends on existing cognitive frames - theories, myths, and mental models-because coded messages derive meaning only in relationship to previously acquired knowledge. Here, I shall refer to all such cognitive frames as "theory" - using the term broadly to include everything from inherited mental maps to scientific theorems.

The "theory" of a practice need not be very articulated in order to be useful. Medieval cathedral builders lacked a theory of structural mechanics but were able to construct extremely complex innovative structures by means of simple rules of thumb that...

... related sizes to spaces and heights by ratios, such as half the number of feet in a span expressed in inches plus one inch will give the depth of a hardwood joist. These rules of thumb were stated as, and learned as, ratios; for, as the span gets larger, the depth of the joist will too. This sort of geometry is extremely powerful. It enables the transportation and transmission of structural experience, it makes possible the successful replication of a specific arrangement in different places and different circumstances, it reduces a wide variety or problems to a comparatively compact series of solutions, and it allows for a flexible rather than rigidly rule-bound response to differing problems. (Turnbull, 1993: 323)

However, the application of these and similar rules of thumb in time proved inadequate to the ambition of architects and their patrons. Like in

\footnotetext{
${ }^{12}$ How well, or for how long articulated knowledge serves the interests of the community is another issue. As it becomes obsolete, previously valuable knowledge may become a liability, acting as an obstacle to learning and change (Leonard-Barton, 1992). However, this liability of knowledge seems to be largely independent of its degree of articulation or codification. Explicit rules may certainly reinforce resistance to change, but both internalized and implicitly acquired knowledge residing in the unreflective unconscious and "packaged in conservative and conserving ways" (Hedlund 1994: 77) are probably equally if not more potent sources of such resistance.
} 
many other crafts and traditional engineering industries, a technological trajectory based on rules of thumb and trial-and-error methods of experimentation eventually reached a point where desired performance improvements became progressively more difficult and eventually prohibitively costly.

In this situation, communities of practitioners may decide to systematically try to develop a more adequate theoretical understanding of the materials and forces involved. Individual practitioners may similarly engage in "reflection-in-action" (Schön, 1983/1996) in order to reach a better understanding of the conditions influencing the task at hand. In both types of situations, the aim is to improve performance by means of knowledge articulation and the development of new and more powerful theory. ${ }^{13}$

\subsection{Codes}

Practitioners require symbolic means of expression and communication. Such symbolic means-here referred to as "codes"-are often an aid for planning and implementation. Indeed, the very performance of a practice may depend on them. But codes are also required for communicating and thinking about the practice, as well as for recording and storing information. Most economically significant codes are explicit, but some have strong tacit elements. The latter include "patterns" of different kinds that carry meaning to a person skilled in the art or profession without her being able to account for precisely how this happens.

Every competent practitioner can recognize phenomena - families of symptoms associated with a particular disease, peculiarities of a certain kind of building site, irregularities of materials or structures - for which he cannot give a reasonably accurate or complete description. (Schön, 1983/1996: 49)

As long as the tacit interpretation of such patterns produces the expected and desired outcomes, there is usually little inducement to develop more explicit codes to capture them or to articulate the knowledge on which they are based. However, at times, unfamiliar patterns may occur that cannot readily be interpreted. Provided that a suitable vocabulary or code can be found or

\footnotetext{
${ }^{13}$ It is worth noting that before theories can be developed and applied to a specific problem, the problem itself must be defined. As Schön (1983/1996: 40) emphasizes, "problem setting. . . is not itself a technical problem." Frequently, both the ends to be achieved and the possible means to be used need to be clarified. Framing the problem is the first step in a process of articulation: "Problem setting is process in which, interactively, we name the thing to which we will attend and frame the context in which we will attend to them" (Schön, 1983/1996: 40, italics in the original).
} 
developed, this may involve the articulation of a new theory or model of the phenomenon. $^{14}$

Language — both ordinary language and more specialized varieties, such as mathematics, chemical formulae, or computer code-and pictorial representations (graphs, maps, diagrams, and pictures, etc.) constitute basic forms of code, some with origins as ancient as humankind. Pictorial codes are significant since many types of knowledge cannot easily be conveyed within the serial logic of mathematics and natural languages. As Hedlund and Zander (1993: 10) note, “... the relationship between the details of a complex skill, even if articulable one by one, is sometimes lost in language, which due to its serial nature cannot simultaneously describe the relationships and characterize the things related." As elaborated subsequently, it is useful, although linguistically awkward, to regard physical artifacts, such as tools and machines, also as forms of articulated knowledge.

The aims of their practice and the goals of communities have a strong influence on the codes they develop and employ. An interesting example is offered by the failed attempt to provide American shipyards with ready-made (British) plans for the construction of the Liberty freighter during World War II (Brown, 2000). In the second half of the 19th century, the engineering cultures of the two countries had begun to diverge. For a variety of reasons, including both the nature of demand and the cost and qualifications of available labor, British manufacturing firms emphasized variety and design creativity (“innovation”), American engineers were more concerned with standardization and production control ("replication"). In consequence, by 1940 the mechanical drawings used in Britain were so different from those employed in the United States as to be literally meaningless in American shipyards.

Over time, increasingly specialized and sophisticated varieties of textual and pictorial code have radically reduced the costs of articulation, permitting articulation of skills previously immune to explication. Innovations as regards the methods for producing, reproducing, and storing text and images have revolutionized the impact of knowledge codification (Dodgson et al., 2005).

\subsubsection{Language}

The availability and characteristics of relevant codes are primary determinants not only of the cost and ease of articulation but also of its potential benefits. Our ability to name things and to express ourselves in writing determines not only the ease or

\footnotetext{
${ }^{14}$ Many phenomena cannot be articulated in ordinary language but require dedicated codes. It appears that in the absence of an efficient vocabulary or code, attempted articulation may in fact negatively interfere with a person's abilities. As Schooler and co-workers have shown, trying to articulate the holistic impression of a complex image, such as that of a face, tends to produce verbally biased memory representations (Schooler and Engstler-Schooler, 1990; Dodson et al., 1997).
} 
difficulty of communicating what we see, It vitally affects our very perception, i.e., our ability to see things in the first place (Ong, 1982). Language and other codes, that we use in communication and that shape our perceptions, are not stable. They develop over time, allowing progressively finer distinctions in the overall stream of experience (Tsoukas and Vladimirou, 2001).

\subsubsection{Pictorial representations}

In the early 15th century, the Renaissance inventions of chiaroscuro (the illusion of the third dimension through shading) and linear perspective provided standard conventions for the pictorial representation of three-dimensional objects (Ivins, 1938/1973; Edgerton, 1976, 1980; Ferguson, 1992/2001). ${ }^{15}$ As Edgerton (1980: 182) notes, these conventions provided a new and powerful code: "The mathematical aspect of Renaissance art also allowed it to be used as a special visual language, particularly when describing tangible objects." These developments, and subsequent graphic inventions such as Cartesian coordinate geometry, orthographic projections, other types of engineering drawings and, more recently, the development of Computer Aided Design, produced a radical change in the ease with which visual information could be conveyed (Booker, 1963; Henderson, 1999; Dodgson et al., 2005).

Based on the invention of printing from woodcuts and engraved metal plates by the mid 15th century, together with Gutenberg's invention of movable type around the same time, these new codes were crucial for both the Scientific Revolution of the 17th century and the Industrial Revolution of the 18th (Ivins, 1938/1973; Ferguson, $1992 / 2001)$. It now became possible to exactly duplicate in large numbers both text and visual information, such as drawings and diagrams. The creation and use of pictorial symbols and associated conventions revolutionized the codification and transmission of both scientific and technological knowledge.

\subsection{Tools}

Practices depend for their execution on "tools," some of rather general utility and range of application, such as pencil and paper, others highly specific to a particular practice. The latter is true of many scientific instruments, for example, that have no use or application outside a narrowly defined range. In the following, the term "tool" will be used in its broadest meaning to denote all the various types of man-made

\footnotetext{
${ }^{15}$ Since they do not show distortions in measurements, drawings in axonometric or isometric perspective are more suitable to many engineering applications, such as specifying dimensions of objects to be produced. However, perspective drawings are superior in depicting the relationships of parts in a complex whole. "Perhaps..." Edgerton (1976: 79) speculates, "...the axonometric drawing enabled the Chinese to jump ahead of the West in technology during the Middle Ages; but linear perspective surely enabled the West to move from technology to a genuine scientific revolution after the Renaissance."
} 
physical artifacts that communities use or produce in the course of their practice. Tools are significant for the articulation process in both immediate and indirect ways. Following Rogers (1983: 2), three classes of tools can be distinguished, differing in the way they allow human beings to relate to the physical world:

Many tools increase the efficiency of the body. This includes a wide variety of tools, ranging from simple hand tools to numerically controlled machine tools and robots, but also transportation equipment and housing, for example. Like all man made objects, they are significant because they embody knowledge-both tacit and otherwise - that went into their making.

A second class of tools serves to increase the efficiency of the senses via instruments that permit measurements of not directly perceivable phenomena or with greater precision and reliability than possible by mere sense perception. Such instrumentalities serve the articulation process by providing data necessary for the formulation, testing, and refinement of theoretical models (de Solla Price, 1984; Crump, 2001; Galison, 2003).

Third, there are tools that increase the power of the human intellect as aids to memory, intelligence, and communication. Such memory tools or cognitive artifacts (Hutchins, 1999) are of special significance in the present context since they serve as media for the codification, storage, and transmission of articulated knowledge.

\subsubsection{Embodied knowledge}

All human artifacts, from the simplest hand tools to advanced rocketry, embody the knowledge employed in their making. "The artifact often is an exemplar of that knowledge, and can sometimes be thought of as a "container" or "storage vessel" for it..." (Cowan et al., 2000: 229f.).

The transfer of embodied technologies increases the skill of the recipient but does not necessarily imply the transfer of the underlying cognitive elements. In the simplest case, the use of the artifact is self-explanatory, requiring no or only limited prior knowledge on part of the receiver. Argote (1999: 69f.), for example, relates the rapid diffusion within a chain of pizza stores of a "cheese spreader" - a tool to help ensure the even distribution of grated cheese on pizzas. Effective use of a "cheese spreader," like that of a personal computer, requires no understanding of the embodied technological principles.

In many instances, such understanding may be irrelevant for the user whose primary interest is the application of the artifact and who may be totally ignorant of the concepts guiding its design and the manufacturing principles employed in its production. Being incidental to their primary purpose, the knowledge embodied in artifacts often has strong tacit elements. Nevertheless, an observer belonging to the relevant community and versed in the appropriate production technologies may through observation and reverse engineering be able to "decode" the artifact and lay bare the knowledge used in its design and production. 


\subsubsection{Instrumentalities}

Articulation and theory development frequently require access to quantitative measurements of phenomena not readily available to natural perception or requiring a level of precision that cannot be obtained without the aid of dedicated instruments. For the development and testing of new theory, such measuring tools"instrumentalities" - are often required. Vincenti's account of the articulation of "flying qualities" offers a good illustration:

The capability at Langley depended crucially on new instrumentation. Warner and Norton's first instruments were primitive: standard altimeter, tachometer, and airspeed meter, plus a graduated sector attached to the rocker arm of the control stick for elevator angle and a ring grip on the control column for stick force. The pilot or observer hurriedly recorded the readings on a kneepad. (Vincenti, 1990: 70)

The causal relationship between instrumentalities and the articulation of theory is not unidirectional. Modeling the double helix structure of DNA critically depended on Rosalind Franklin's techniques to produce X-ray diffraction pictures (Watson, 1968). In contrast, it was almost a century after the publication of the Principia that Atwood invented an apparatus to empirically demonstrate the workings of Newton's second law (Kuhn, 1977: 189).

\subsubsection{Memory tools}

Memory tools and other cognitive artifacts are significant, first of all, because of their material properties - they can be stored and transported and are therefore able to bridge both time and space. Many, such as archives and data banks, are created precisely for these reasons. The same is true for other objects used and produced in the process of knowledge codification, such as printed paper, blueprints, and computer hardware. But objects created for other purposes are also often used in support of human memory (Hutchins, 1995b, 1999).

The templates used in the building of 13th century Gothic cathedrals offer an early example. Without the benefit of precise measurements, scale plans or theory of structural mechanics, portable templates, embodying geometrical rules of thumb, provided the powerful means by which complex knowledge was replicated and transmitted, facilitating accurate mass production and the coordination of a large number of workers:

The template helps to make possible the unified organization of large numbers of men with varied training and skill over considerable periods of time.... In addition to the power to organize large numbers of workers, templates have the power to allow for greater exactness of stone cutting and enabled a stable, enduring, and coherent structure, despite a discontinuous process and radical design changes.... 
The template... provides a structure whose stability is achieved despite the lack of what we would take to be the basic essentials for producing the specifications for a particular element in a building, a common and precise mode of measurement, a knowledge of structural mechanics, and a detailed scale plan. (Turnbull, 1993: 322f.)

Numerically controlled machine tools offer a modern day example. Complex metal cutting, for example, is slow and difficult when performed manually but can be coded with relative ease and ensured precision. And, once coded, the commands can be stored and the task need not be analyzed again.

\section{Benefits and costs of articulation}

\subsection{Articulation and knowledge creation}

Articulation-the conversion of tacit into explicit knowledge-is fundamental to knowledge creation and innovation (Zollo and Winter, 2002). Indeed, it is a prerequisite for rapid and cumulative learning. Of course, learning can also take place without suitable codes and vocabularies - as when baseball pitchers learn to "find the groove" (Schön, 1983/1996: 54). However, such learning is slow, cumbersome, and difficult to pass on to others. In consequence, the state-of-the-art of the community of baseball players advances only slowly over time. Joe DiMaggio would still command a handsome reward in the World Series. In contrast, the alpine skiers of by-gone days would only with difficulty qualify for a spot in the World Cup. Here, learning has been rapid and cumulative because it has been articulated and embedded in new materials and shapes of skiing equipment. Today's alpine skiers are better able to ski (e.g., faster down steeper hills) than their predecessors not, at least not to any considerable extent, because they are better skiers, but because they profit from the accumulated knowledge embodied in the skis they use.

Analogously, today's cars are better than yesterday's not because modern engineers are smarter or more creative than their predecessors, but because they can draw on more knowledge and experience of car making, as articulated and codified in textbooks and engineering manuals and as embodied in components and production equipment. Conversely, had the art of automobile manufacturing remained as a largely unarticulated craft, we would not have seen the rapid learning and technological change that has, in fact, taken place. Seemingly trivial as these principles may appear, modern day car factories display marked differences in their ability to accommodate and exploit them (Adler and Cole, 1983).

Ever since the Scientific Revolution of the 17th century, we have seen a continuous trend away from the experiential and tacit rules of craftsmen towards articulated substantive and operative theories of technology (Bunge, 1966). Technical progress is today more rapid than in the past, not because present day innovators are 
more creative than those of the past, but because they have access to a vastly expanded range of articulated knowledge. Modern technology is unthinkable without codification.

The trend towards increasing articulation and codification is perhaps most obvious and pervasive in science and engineering, but it has also been a force in the development of modern management techniques, at least since the mid 19th century. Before this time, business firms tended to keep few records other than accounts and business correspondence (Chandler, 1977; Yates, 1989). Like in production, much vital knowledge was unarticulated:

In the early nineteenth century, organizational memory in American firms consisted of the memories of individuals, simple routines, and very limited records. Most firms were managed by their owners, who carried much of the knowledge of business methods and past successes and failures in their heads. These owner/managers/were often aided by skilled artisans, who in turn carried most of the knowledge of technical methods in their heads and hands. Both owners and skilled employees applied their knowledge through simple standard procedures and through oral orders. This knowledge could be passed on only by prolonged apprenticeship, either technical or managerial. (Yates, 1990: 173)

By the early 1900s, the traditional reliance (and dependence) of firms on the skills and memories of individuals (both owner/managers and employees) was increasingly replaced by written records, reports, and manuals, codifying organizational rules and procedures. The introduction of "systematic management" reflected not only an attempt "... to transcend dependence upon the skills, memory, or capacity of any single individual" but also "an attempt to rise above the concrete details of the task to think about what is being done, rather than merely to do it" (Jelinek, 1980: 64, italics added).

This is not meant to suggest that in the modern world there are no traditional industries characterized by highly tacit technologies, nor that modern, "sciencebased" industries are totally independent of such knowledge. Many of the skills of managers and much of the creativity underlying new innovations are, by their very nature, inarticulable, And, as emphasized above, efficient deployment of newly developed theory, tools, and code frequently requires implicit, experiential learning. However, the argument does mean to imply that, if at all, such tacit elements develop only slowly. Articulation is the primary force in knowledge creation and the formation of new capabilities.

\subsection{The benefits of articulation}

Articulation and codification of tacit knowledge have several specific benefits, which together help to account for the technical, scientific, and economic progress of 
human civilization since the invention of writing by the Sumerians around 3000 B.C. Historically, the combined and cumulative effects of new codes, new theory, and new tools have made possible the articulation of ever-larger areas of knowledge. Lately, advances in the fields of electronics, computer science, and scientific instruments have dramatically increased the range of skills and knowledge amenable to articulation while drastically reducing the associated costs. Of course, their impact on the production, replication, dissemination, and storage of codified knowledge has been no less dramatic.

Once they are available, new codes often make possible the development of new models and new theory. New theory, in turn, may lead to the refinement of existing codes or the creation of new ones. However, articulation always requires effort, especially when both codes and methods of measurements must first be invented and developed.

The decision as to whether or not to engage in articulation and incur the associated investments will be determined by the expected benefits, the value attached to these benefits and by the cost and effort required. (Sanchez, 1997; Cowan et al., 2000). The effort will only be undertaken and the costs will only be incurred if they are expected to generate benefits in excess of these costs.

This is not to say that the process can be described as "an exercise in equilibrating marginal benefits and costs" (Johnson et al., 2002: 257), nor can we assume that an equilibrium exist where no further benefits from articulation can be expected. In an evolutionary context, it is not difficult to imagine that fully rational economic agents may have an incentive to continuously increase the degree of codification of their knowledge. Indeed, outside the realm of neo-classical economic models, this would appear to be the rule rather than the exception.

Of course, articulation and the development of new codes are not exclusively responses to rational economic calculation; in medieval Europe, they first served the interests of religion and warfare, only later those of more purely economic aims. The development of linear perspective and the geometrical quantitative qualities of Renaissance art have been traced to the 13th century cult of St. Francis, which inspired painters to revive ancient Greek and Roman traditions in an effort to render the holy myths as realistically as possible (Edgerton, 1980: 184ff.). Architectural plans were first developed at the construction sites of Gothic cathedrals in the 13th century, the primary "high-tech" activity of its day. By the middle of the 15th century, technical drawings were used to depict drawings of civil devices, such as cranes, mills, or pumps, but their earliest applications were to weaponry and various kinds of assault devices (Lefèvre, 2004).

Thus, decisions as to whether or not to engage in codification reflect not only economic incentives but also inherited, culturally based value- and belief-systems. In Europe, Protestant printers and Protestant ideology were instrumental in opening the way for the Scientific Revolution and in overcoming the alliance between the theology of the Catholic Church and the teachings of Aristotle (Eisenstein, 1983). 
In China, in spite of the potential of Mohist logic and Taoist natural insight, Confucian dominance prevented a similar unfolding of scientific thinking (Needham, 1978).

Beliefs, attitudes, and habits also affect the articulation activities of modern-day communities. Some tend to attach more value to articulation than do others (Wright, 1997). R\&D units, for example, differ strongly in this respect. Some are strongly "normatively-oriented" (Hofstede et al., 1990; Håkanson, 1995), aiming for a scientific/theoretical understanding of production processes. Others are much more "pragmatic" and consider such understanding superfluous as long as the processes deliver the right quality of product in appropriate quantities. They tend to view articulation activities and codification systems as bureaucratic and wastefully time consuming. Similar attitudes are found among scientists, who are often reluctant to document improvements in laboratory techniques, since their publication may only be possible in less prestigious journals (Cambrosio and Keating, 1988: 253).

The conditions and inducements for undertaking the investment necessary for articulation have differed over time and differ between contexts. Although interrelated, three broad categories of benefits can be identified: innovation, division of labor, and replication and control.

\subsubsection{Innovation}

One of the most powerful effects of articulation is to enhance the possibilities for experimentation and innovation. In the absence of codification, there is no symbolic means to predict whether a new design will work. The only way to find out is to build and subject it to actual conditions of use. Should the design fail, the time, work, and materials involved may have been wasted. In consequence, craft production is inherently conservative, characterized by a very slow rate of innovation and change (McGee, 1999).

As already noted, articulation can never fully retain the richness or completeness of the original skill. However, precisely because it conveys only a part of the original knowledge-articulation helps focus attention on its critical aspects. This account for the power of drawings as a method of design: "Articulation pictures the essentials of a situation on a reduced scale, which lends itself more easily to imaginative manipulation than the ungainly original; it thereby makes possible the science of engineering." (Polanyi, 1962: 85, italics added)

The emergence of modern methods of engineering - "the shift from craftsmanship to draftsmanship"-was made possible by the Renaissance development of linear perspective and the use of drawings as a method of design (Ferguson, 1992/ 2001; McGee, 1999). Already in the early 15th century, Taccola and his contemporaries were exploiting the new conventions of pictorial representation, such as the "exploded view" and the "transparent view" to design machines solely by 
means of drawings, without having to find a patron to finance expensive constructions (Edgerton, 1980: 195).

The method of "design-by-drawing" was later extended to the use of measured drawings, specifying the dimensions of products before their actual production using two-dimensional orthographic projections. This accelerated the rate of innovation by allowing designers/inventors to experiment with the geometrical aspects of proposed designs without the costs and effort of constructing and altering the product itself. ${ }^{16}$ It also consolidated the role of drawings as the preferred medium for communication of technical information (Henderson, 1999). The mastery of drawings as a means of experimentation and of mathematics as its language is a distinguishing feature of the modern engineer (Petroski, 1996: 89f.).

Articulation also increases the level of complexity that can be managed. Codification makes it possible to "chunk," store and communicate technological knowledge. This too is exemplified in the use of drawings which enabled engineers and designers to deal with a hitherto "unmanageable, and unimaginable, degree of complexity" (McGee, 1999: 28), unmatched until the advent of Computer Aided Design.

\subsubsection{Division of labor}

A further primary benefit of articulation is to facilitate the division of labor. Traditional craft production is undifferentiated and continuous. Artifacts are created without explicit design, using techniques that are largely tacit. The passing on of these techniques is time consuming and therefore costly. Time spent in instruction detracts from time in production. This limits the number of apprentices that a master can supervise at any one time and, thereby, his opportunity to exploit advantages of specialization and division of labor. In pre-industrial Europe, these limits were reinforced by the institutional setting of the time, e.g., the rules of guilds and the moral sanctions of the church. ${ }^{17}$

The introduction of drawings as a method of design had consequences also for the division of labor. It allowed a separation between design and production; these activities could now be undertaken at different times, by different people, and at different geographical locations. Moreover, the use of measured drawings radically

\footnotetext{
${ }^{16}$ One of Henderson's (1999: 82) informants expresses the importance of drawings for design innovation: "You can't sit there and wait until you have it up here because it comes through drawing it. And as soon as you start drawing it, you have ideas and changes. You're erasing it and improving it. And they say the best designers start drawing right from the beginning. That's where they make all their mistakes... They're visually checking it and improving upon it..."

${ }^{17}$ In spite of these restraining forces, the middle ages saw a continuous proliferation in the number of guilds, a reflection of an apparently irresistible increase in specialization and division of laborboth associated with articulation and learning (Braudel, 1979/1982: 314ff.).
} 
facilitated the planning and execution of projects, such as large ships or buildings that were too big for a single craftsman to make.

Equally important, by enhancing division of labor and specialization, articulation can lead to dramatic improvements in productivity. The advantage of time-andmotion studies in the scientific management tradition of Fredrick W. Taylor was not only the increased productivity of the individual worker. At least as important was the transformation of work itself, from skilled or semi-skilled craft production to unskilled manufacturing jobs. For firms and their owners, deskilling and increasing division of labor created benefits through savings in labor cost and through reduced dependence on skilled artisans. For individual workmen and organized labor, the effects were predominantly negative (Braverman, 1974).

\subsubsection{Replication and control}

A common incentive for articulation and codification is to reduce the cost of capability replication. This applies, for example, to the acquisition of firm specific skills by new employees. Time spent in acquiring tacit organizational knowledge is unproductive and costly. Reduction in learning times can bring considerable savings.

Another common case of capability replication is technology transfer to licensees, joint venture partners, or wholly owned subsidiaries. Empirical research has shown that the costs for such transfers are often considerable, depending on factors such as the sender's experience with prior transfers and with the technology, the skills and experience of the receiver and the characteristics of the technology itself, notably its degree of codification (Teece, 1977; Contractor, 1981; Kogut and Zander, 1993; Zander and Kogut, 1995).

A related reason for articulation is to improve "control," i.e., the precision and reliability with which a particular organizational routine can be performed. The quest for increasing control is the dominating theme in the seminal works of Beniger (1986) on the historical development of information technologies and Yates (1989) on the "systematic management" movement. Although not framed in these terms, both can be read as pioneering studies in the power and logic of articulation.

Following Chandler (1977), Yates (1989) describes, for example, how, in the mid 19th century, the need to reliably manage, coordinate, and control geographically dispersed operations led American railroads to pioneer major innovations in cost accounting, planning procedures, and operational reporting. The quest for control and the rise of the Chandlerian multidivisional enterprise were co-evolutionary, mutually reinforcing processes (Langlois, 2003: 273). Explication and codification of organizational procedures remain central to controlled replication and "quality management"- they are important elements, for example, in ISO 900x certification. However, since the end of the 20th century, widespread vertical disintegration has increasingly come to replace the large multi-divisional firm in many industries. The benefits of control and coordination that articulation confers appear to have been overtaken by its potential to promote specialization and a division of labor. 
Intriguingly, the standardization and modularization that now enable market forces to replace hierarchical control seem to have resulted, in part at least, from the quest for interchangeability as a means to improve that very control (Langlois, 2003).

\subsection{Articulation and politics}

As in the case of technical progress generally, articulation usually brings benefits to some and costs to others. Braverman (1974: 18) recalls Marx's famous statement:

Social relations are closely bound up with productive forces. In acquiring new productive forces men change their mode of production; and in changing their mode of production, in changing the way of earning their living, they change all their social relations. The hand-mill gives you society with the feudal lord; the steam mill, society with the industrial capitalist. (Marx, n. d.: 92 in Braverman, 1974: 18)

The Marxist tradition emphasizes the alienation and exploitation of the working class as the primary effects of articulation and technical change: "The more science is incorporated into the labor process, the less the worker understands of the process; the more sophisticated an intellectual product the machine becomes, the less control and comprehension of the machine the worker has" (Braverman, 1974: 73).

By the mid 19th century, the introduction of engineering drawings following standardized conventions radically changed the balance of power between engineers, managers, and workers (Henderson, 1999). It reduced the discretion of foremen in the shops by transferring decisions to the drafting rooms, from where complete specifications were issued according to which work was to be done:

The transformation that occurred in most European and American shops in the nineteenth century was from a world in which engineers negotiated with workers who had traditionally used the judgment of their trades to a world in which matters of judgment were settled by pencils on paper in drafting rooms remote from the shop floor. The removal of all discretionary power was neither sudden nor uncontested, but within a few decades the center of authority in engineering work was clearly located in engineering drawings. (Ferguson, 1992/2001: 102)

Articulation, like innovation and technological progress, almost always entails a redistribution of knowledge and skills. It has repercussions both on the equilibrium conditions in the economy and on the power balance of the social systems it affects. The articulation of the traditional and largely tacit knowledge concerning the delivery of babies has brought a power shift from (predominantly female) midwives to (predominantly male) physicians-legitimated by the associated reduction in infant mortality rates. More generally, articulation, codification, and ordering are essential to the professionalization of knowledge, as communities of practitioners 
ascertain their claim to certain knowledge bases (through educational systems, credentialing and professional associations) in order to "translate one order of resources (specialized knowledge and skills) into another (social and economic rewards)" (Henderson, 1999: 24). Articulation is not only an economic process with economic consequences; it is often a more or less intensely political process with substantial social consequences. Indeed, it is worthy of study not only because of its economic effects but also, and perhaps primarily, because of its social and political consequences.

\section{Implications}

Although the details of this remain to be worked out, the conceptual framework outlined earlier can be applied at different analytical levels to inform our understanding of the knowledge creation activities in communities of practitioners. On the smallest analytical level, that of groups, the literature on distributed cognition displays interesting parallels. It provides rich evidence on the cognitive processes that take place in the interactions between human beings and technological and natural artifacts in their physical environment, including their representations (Hutchins, 1995a, b; Hutchins and Klausen, 1996; Hutchins and Palen, 1997).

Most studies in this tradition have focused on small socio-technical systems, such as the bridge of a ship or the cockpit of an aircraft. However, many of the central characteristics of distributed cognition apply also at other societal levels, as does the interplay of the elements of the "articulation circle" (Hollan et al., 2000). Analog processes take place in larger groups, such as professional communities whose members manage, often without intensive interaction, to develop, maintain, and nurture the knowledge, which informs their practice. They are also important for more epistemologically heterogeneous groups of people, such as firms and other organizations. As demonstrated elsewhere (Håkanson, 2006), commonalities of language ("codes"), "boundary objects"18 such as blueprints and computer systems ("tools") and a shared corporate culture ("theory") enable organizations to achieve integration and coordination of occupational groups with diverse practices and cognitive traditions (Lawrence and Lorsch, 1967; Grant, 1996a, b).

Similar processes can be identified at the level of industries, where the concentration or distribution of cognitive tasks among and between firms and other organizations has fundamental effects on the rate and direction of technological progress. A recent analysis by Garud and Karnøe (2003) of the

\footnotetext{
${ }^{18}$ On the role of "boundary objects" as facilitators of organizational communication across occupational groups see Star (1989); Bowker and Star (1999); Carlile, (2002); Bechky (2003a, b) and Carlile and Rebentisch (2003).
} 
technological learning processes in the wind turbine industries in Denmark and the United States illustrates some of the implications of the proposed perspective. ${ }^{19}$

Danish producers and designers started out with little or no knowledge of aerodynamics or the relevant structural dynamics. Many were small machine shops with only one or two engineers. Vestas, the current industry leader, was a manufacturer of agricultural trailers, coolers for ship engines, and hydraulic cranes for light trucks. Without prior experience and without much pertinent theoretical knowledge, Danish engineers initiated a process of incremental trial-and-error learning, utilizing simple engineering heuristics, such as the practice of "throwing metal" at failing components (Garud and Karnøe, 2003: 285). The experience gained was systematically codified by The Danish Wind Turbine Test Station (DTWS) at Risø with which the manufacturers had to cooperate in order to get approval for their designs. The creation of new codes and standards permitted uniform tests and measurements-data that later provided vital empirical input for advanced theoretical modeling of aerodynamic and structural effects. In the terms of the simple model depicted in Figure 2, this market-driven approach to innovation can be described as a circular clock-wise movement with its origin in "tools," i.e., the various components of the turbines.

In the United States, the leading industry innovators were engineering-based companies, many with experience from the aerospace industry. Their expertise and background, in combination with the science-based bias of Government agencies and funding schemes, led them to pursue maximum aerodynamic efficiency, exploiting advanced materials technology in light-weight designs. In terms of Figure 2, this "mission oriented" technology-driven approach to innovation (Ergas, 1987) attempted to proceed clockwise from "theory." ${ }^{20}$ With the benefit of hindsight, it is now appears that the knowledge of the aerodynamic and structural properties of propellers and helicopter blades was largely inapplicable to wind turbines and sometimes directly misleading. But of more immediate interest for the present argument are the institutional conditions in the United States, which obstructed the coupling of cognitive advances in theory, codes, and tools construction, thereby slowing the rate of technological learning. Design and manufacturing in the American companies were often poorly integrated, isolating "theory" from "tools" and leading design engineers to pursue radical improvements with little regard to practical feasibility. Moreover, mutual rivalry and concern for secrecy obstructed the

\footnotetext{
${ }^{19}$ In addition to Garud and Karnøe's (2003) excellent summary, the account draws on Karnøe (1991, 1999) and Gipe (1995).

${ }^{20}$ As one of the leading American wind turbine engineers put it: “...(1) We [engineers] felt bright and able to solve anything, (2) we thought in a typical American fashion that there would be inevitable breakthroughs that would make the 'pedestrian' Danish approach obsolete overnight." (Woody Stoddard in Karnøe, 1999: 161).
} 
development of new codes and standardized testing procedures which would have facilitated the development of more relevant and more accurate theoretical models.

The aim of this brief example is not to suggest that distributed learning is always superior to more concentrated varieties, nor that market-driven technological change is always more efficient than technology-driven approaches. The contrasting experiences in the two countries have been summarized to illustrate the importance of the interaction of "theory," "codes," and "tools" in the technological development of an industry. They also show the significant potential for "distributed agency" in these processes and that the design of the interaction between agents can have dramatic effect on the outcome. Most significantly, the example demonstrates that more attention should be paid to the organizational design of the articulation process, especially to the institutional and socio-technical conditions that affect the division of labor within it, but also to the interaction and organizational embeddedness of the various actors.

In the science policy literature, in the discussion of resource-based competitive advantage and in the so-called knowledge-based theory of the firm, much attention has been given to the questions of how and if increased codification of knowledge affects the ease or difficulty of its voluntary dissemination or involuntary imitation. While these are certainly important questions, the preceeding analysis suggests that more attention should be given to the knowledge creating aspects of articulation, i.e., the dynamics whereby investments in explication and codification tends to enhance both tacit and codified knowledge.

\section{Conclusions}

In the larger context, of course, the recent focus on tacit knowledge reflects a reaction against the claims of the rationalist philosophical schools that have dominated Western thinking since the time of Galileo. There is no doubt that the works of Heidegger (1927/1996) and Polanyi (1962, 1966), for example, have considerably informed and enriched the management sciences by their critique of rationalist assumptions. However, in spite of its merits, it is the claim of this article that, in the management sciences, the recent emphasis on "tacit knowledge" has come at the cost of neglecting other and more dynamic aspects of knowledge: the role of "articulation" and "codification", i.e., the process through which tacit knowledge is made explicit.

The concept of "tacit knowledge" as invoked, for example, in the seminal contributions of Nelson and Winter (1982), Winter (1987), and Kogut and Zander (1992, 1993) has played an important role in directing our attention to the fundamental role of knowledge for management, organization, and strategy. However, in much recent literature, it has become all too common to dismiss codified knowledge as being (automatically) easily imitated, hence, unable to provide competitive advantage and, hence, uninteresting. 
Tacit skills, such as charismatic leadership and creative engineering are certainly scarce, valuable and difficult-to-imitate resources (Barney, 1991). But not being susceptible to articulation, they develop only slowly over time. As outlined in this article, innovation and new knowledge creation take place through articulation, in the interactive development of new codes, new tools, and new theory. It appears that most forms of economically relevant knowledge can be articulated and that articulation often has far-reaching consequences for the social and economic systems where it takes place.

However, and in spite of its obvious significance, the available knowledge on the conditions affecting the articulation process and on its social, economic, and managerial implications has yet to be synthesized into a coherent theory. The aim of the model outlined earlier is to encourage the reopening of an empirical and theoretical research agenda, focusing on the determinants, mechanisms, and effects of knowledge creation, not only in groups, professional communities and firms, but also in entire industries.

\section{Acknowledgements}

The supportive encouragement and constructive criticism provided by many friends and colleagues, especially Jonathan Bayliss, Rajneesh Narula and Peter Karnøe, are gratefully acknowledged.

\section{Address for correspondence}

Lars Håkanson, Department of International Economics and Management, Copenhagen Business School, Porcelænshaven 24, DK-2000 Frederiksberg, Denmark. Email: lh.int@cbs.dk

\section{References}

Adler, P. S. and R. E. Cole (1983), 'Designed for learning: a tale of two auto plants,' Sloan Management Review, 25(Spring), 85-94.

Argote, L. (1999), Organizational Learning: Creating, Retaining and Transferring Knowledge. Kluwer: Boston.

Baldwin, T. T. and J. K. Ford (1988), 'Transfer of training: a review and directions for future research,' Personnel Psychology, 41, 63-105.

Barney, J. B. (1991), 'Firm resources and sustained competitive advantage,' Journal of Management, 17, 99-120.

Bechky, B. A. (2003a), 'Object lessons: workplace artifacts as representations of occupational jurisdiction,' American Journal of Sociology, 103, 720-752. 
Bechky, B. A. (2003b), 'Sharing meaning across occupational communities: the transformation of understanding on a production floor,' Organization Science, 14, 312-330.

Beniger, J. R. (1986), The Control Revolution. Technological and Economic Origins of the Information Society. Harvard University Press: Cambridge, MA.

Berman, S. L., J. Down and C. W. L. Hill (2002), 'Tacit knowledge as a source of competitive advantage in the national basketball association,' Academy of Management Journal, 45, $13-31$

Boisot, M. (1995), Information Space: A Framework for Learning in Organizations, Institutions and Culture. Routledge: London.

Boisot, M. and J. Child (1988), 'The iron law of fiefs: bureaucratic failure and the problem of governance in the chinese economic reforms,' Administrative Science Quarterly, 41, 507-527.

Boisot, M., D. Griffiths and V. Moles (1997), 'The dilemma of competence: differentiation versus integration in the pursuit of learning,' in R. Sanchez and A. Heene (eds), Strategic Learning and Knowledge Management. Wiley: Chichester, pp. 65-82.

Booker, P. (1963), A History of Engineering Drawing. Chatoo \& Windus: London.

Bowker, G. C. and S. L. Star (1999), Sorting Things Out. MIT Press: Cambridge, MA.

Braudel, F. (1979/1982), The Wheels of Commerce: Civilization and Capitalism, 15th-18th Century, Volume 2. HarperCollins: London.

Braverman, H. (1974), Labor and Monopoly Capital. Monthly Review Press: New York.

Brown, J. K. (2000), 'Design plans, working drawings, national styles: engineering practice in great britain and the united states, 1775-1945,' Technology and Culture, 41, 195-238.

Brown, J. S. and P. Duguid (1998), 'Organizing knowledge,' California Management Review, 40, 90-111.

Brown, J. S. and P. Duguid (2000), The Social Life of Information. Harvard Business School Press: Cambridge, MA.

Bunge, M. (1966), 'Technology as applied science,' Technology and Culture, 7, 329-347.

Cambrosio, A. and P. Keating (1988), “'Going monoclonal”: art, science and magic in the dayto-day use of hybridoma technology,' Social Problems, 35(Special Issue), 244-260.

Carlile, P. R. (2002), 'A pragmatic view of knowledge and boundaries: boundary objects in new product development,' Organization Science, 13, 442-455.

Carlile, P. R. and E. S. Rebentisch (2003), 'Into the black box: the knowledge transformation cycle,' Management Science, 47, 1180-1195.

Chandler, A. D. Jr (1977), The Visible Hand: The Managerial Revolution in American Business. Harvard University Press: Cambridge, MA.

Cohen, W. M. and D. A. Levinthal (1990), 'Absorptive capacity: a new perspective on learning and innovation,' Administrative Science Quarterly, 35, 128-152.

Contractor, F. (1981), International Technology Licensing. Lexington Books: Lexington, MA. 
Cowan, R., P. A. David and D. Foray (2000), 'The explicit economics of knowledge codification and tacitness,' Industrial and Corporate Change, 9, 211-253.

Crump, T. (2001), Science: As Seen through the Development of Scientific Instruments. Constable and Robinson: London.

de Solla Price, D. J. (1984), 'The science/technology relationship, the craft of experimental science, and policy for the improvement of high technology innovation,' Research Policy, 13, $3-20$.

Dodgson, M., D. Gann and A. Salter (2005), Think, Play, Do: Technology, Innovation and Organization. Oxford University Press: Oxford.

Dodson, C. S., M. Johnson and J. W. Schooler (1997), 'The verbal overshadowing effect: why descriptions impair face recognition,' Memory and Cognition, 25, 129-139.

Edgerton, S. Y. Jr (1976), 'Linear perspective and the western mind: the origins of objective representation in art and science,' Cultures, 3, 77-104.

Edgerton, S. Y. Jr (1980), 'The renaissance artist as quantifier,' in M. A. Hagen (ed.), The Perception of Pictures, Volume I. Academic Press: New York, pp. 179-212.

Eisenstein, E. L. (1983), The Printing Revolution in Early Modern Europe. Cambridge University Press: Cambridge.

Ergas, H. (1987), 'The importance of technology policy,' in P. Dasgupta and P. Stoneman (eds), Economic Policy and Technological Performance. Cambridge University Press: Cambridge, pp. 51-96.

Ferguson, E. S. (1992/2001), Engineering and the Mind's Eye. MIT Press: Cambridge, MA.

Galison, P. (2003), Einstein's Clocks, Poincarés Maps. W.W. Norton \& Company: New York, NY.

Garud, R. and P. Karnøe (2003), 'Bricolage versus breakthrough: distributed and embedded agency in technology entrepreneurship,' Research Policy, 32, 277-300.

Gipe, P. (1995), Wind Energy Comes of Age. John Wiley \& Sons: New York.

Goodwin, C. (1997), 'The blackness of black: color categories and situated practice,' in L. B. Resnick, R. Säljö, C. Pontecorvo and B. Burge (eds), Discourse, Tools and Reasoning: Essays on Situated Cognition. Springer: Berlin.

Grant, R. M. (1996a), 'Toward a knowledge-based theory of the firm,' Strategic Management Journal, 17(Winter Special Issue), 109-122.

Grant, R. M. (1966b), 'Prospering in dynamically competitive environments: organizational capability as knowledge integration,' Organization Science, 7, 375-387.

Grant, R. M. and C. Baden-Fuller (1995), 'A Knowledge-Based Theory of Inter-Firm Collaboration,' Academy of Management Proceedings. Academy of Management: New York, pp. 17-21.

Håkanson, L. (1995), 'Learning through acquisitions: management and integration of foreign R\&D Laboratories,' International Studies in Management and Organization, 25, $121-157$. 
Håkanson, L. (2006) 'The firm as an epistemic community: a research agenda,' Working Paper, Department of International Economics and Management, Copenhagen Business School.

Hedlund, G. (1994), 'A model of knowledge management and the N-form corporation,' Strategic Management Journal, 15(Special Issue), 73-90.

Hedlund, G. and I. Nonaka (1993), 'Models of knowledge management in the west and Japan,' in P. Lorange, B. G. Chakravarthy, J. Roos and H. Van de Ven (eds), Implementing Strategic Processes, Change, Learning and Cooperation. Basil Blackwell: London, pp. 117-144.

Hedlund, G. and U. Zander (1993), Architectonic and List-Like Knowledge Structuring: A Critique of Modern Concepts of Knowledge Management,' Research Paper 1993/2. Institute of International Business, Stockholm School of Economics.

Heidegger, M. (1927/1996), Being and Time. State University of New York Press: Albany, NY.

Henderson, K. (1999), On Line and On Paper: Visual Representations, Visual Culture, and Computer Graphics in Design Engineering. MIT Press: Cambridge, MA.

Hofstede, G., B. Neuijen, D. D. Ohayv and G. Sanders (1990), 'Measuring organizational cultures: a qualitative and quantitative study across twenty cases,' Administrative Science Quarterly, 35, 286-316.

Hollan, J. D., E. Hutchins, E. and D. Kirsh (2000), 'Distributed cognition: a new foundation for human-computer interaction research,' ACM Transactions on Human-Computer Interaction (TOCHI), 7(Special Issue), 174-196.

Hutchins, E. L. (1995a), Cognition in the Wild. MIT Press: Cambridge, MA.

Hutchins, E. L. (1995b), 'How a cockpit remembers its speeds,' Cognitive Science, 13, 265-288.

Hutchins, E. L. (1999), 'Cognitive artifacts,' in R. A. Wilson and F. C. Keils (eds), The MIT Encyclopedia of the Cognitive Sciences. The MIT Press: Cambridge, MA, pp. 126-128.

Hutchins, E. L. and T. Klausen (1996), 'Distributed cognition in an airline cockpits,' in Y. Engeström and D. Middleton (eds), Cognition and Communication at Work. Cambridge University Press: Cambridge, pp. 15-34.

Hutchins, E. L. and L. Palen (1997), 'Constructing meaning from space, gesture and speech,' in L. B. Resnick, R. Säljö, C. Pontecorvo and B. Burge (eds), Discourse, Tools and Reasoning: Essays on Situated Cognition. Springer: Berlin, pp. 15-34.

Ivins, W. M. Jr (1938/1973), On the Rationalization of Sight. Da Capo Press: New York.

Ivins, W. M. Jr (1953/1969), Prints and Visual Communication. Da Capo Press: New York.

Jelinek, M. (1980), 'Toward systematic management: alexander hamilton church,' Business History Review, 54, 63-79.

Johns, A. (1998), The Nature of the Book: Print and Knowledge in the Making. University of Chicago Press: Chicago, IL.

Johnson, B., E. Lorenz and B.-Å. Lundvall (2002), 'Why all this fuss about codified and tacit knowledge?,' Industrial and Corporate Change, 11, 245-262. 
Karnøe, P. (1991), Dansk Vindmølleindustri - En Overraskende International Succes. Samfundslitteratur: Copenhagen.

Karnøe, P. (1999), 'When low-tech becomes high-tech: the social construction of technological learning processes in the danish and the american wind turbine industry,' in P. Karnøe, P. H. Kristensen and P. H. Andersen (eds), Mobilizing Resources and Generating Competencies: The Remarkable Success of Small and Medium-sized Enterprises in the Danish Business System. Copenhagen Business School Press: Copenhagen, pp. 139-185.

Kogut, B. and U. Zander (1992), 'Knowledge of the firm, combinative capabilities, and the replication of technology,' Organization Science, 3, 384-397.

Kogut, B. and U. Zander (1993), 'Knowledge of the firm and the evolutionary theory of the multinational corporation,' Journal of International Business Studies, 24, 625-645.

Kreiner, K. (2002), 'Tacit knowledge management - the role of artifacts,' Journal of Knowledge Management, 6, 112-123.

Kuhn, T. S. (1977), The Essential Tension. University of Chicago Press: Chicago.

Langlois, R. N. (2003), 'The vanishing hand: the changing dynamics of industrial capitalism,' Industrial and Corporate Change, 12, 351-385.

Lawrence, P. R. and J. W. Lorsch (1967), Organization and Environment: Managing Differentiation and Integration. Harvard University Press: Boston, MA.

Lefèvre, W. (ed.) (2004), Picturing Machines 1400-1700. MIT Press: Cambridge, MA.

Leonard, D. and S. Sensiper (1998), 'The role of tacit knowledge in group innovation,' California Management Review, 40(3), 112-132.

Leonard-Barton, D. (1992), 'Core capabilities and core rigidities: a paradox in managing new product development,', Strategic Management Journal, 13(Special Issue), 111-126.

March, J. G. and H. Simon (1958), Organizations. Wiley: New York.

Marx, K (n.d. /1995) The Poverty of Philosophy, Prometheus Books: New York.

McGee, D. (1999), 'From craftsmanship to draftsmanship,' Technology and Culture, 40, 209-236.

Melcher, J. and J. W. Schooler (1996), 'The misremembrance of wines past: verbal and perceptual expertise differentially mediate verbal overshadowing of taste,' Journal of Memory and Language, 35, 231-245.

Mohammed, S. and B. C. Dumville (2001), 'Team mental models in a team knowledge framework: expanding theory and measurement across disciplinary boundaries,' Journal of Organizational Behavior, 22, 89-106.

Morgan, M. H. (ed.) (1914), Vitruvius: The Ten Books on Architecture. Harvard University Press: Cambridge, MA.

Needham, J. (1978), The Shorter Science \& Civilisation in China, Volume 1. (Abridgement of the original text by C. A. Ronan.). Cambridge University Press: Cambridge. 
Nelson, R. R. and S. G. Winter (1982), An Evolutionary Theory of Economic Change. Harvard University Press: Cambridge, MA.

Nightingale, P. (2003), 'If nelson and winter are only half right about tacit knowledge, which half? A searlean critique of 'codification,' Industrial and Corporate Change, 12, 149-183.

Nonaka, I. (1991), The Knowledge-Creating Company. Harvard Business Review, (NovemberDecember), pp. 96-104.

Nonaka, I. and H. Takeuchi (1995), The Knowledge-Creating Company. Oxford University Press: Oxford.

Ong, W. J. (1982), Orality and Literacy: The Technologizing of the World. Methuen: London.

Orr, J. E. (1996), Talking About Machines: Ethnography of a Modern Job. Cornell University Press: Ithaca.

Petroski, H. (1996), Invention by Design. How Engineers Get from Thought to Thing. Harvard University Press: Cambridge, MA.

Polanyi, M. (1962), Personal Knowledge: Towards a Post-Critical Philosophy. Harper and Row: New York.

Polanyi, M. (1966), The Tacit Dimension. Doubleday: Garden City, NY.

Prahalad, C. K. and R. Bettis (1986), 'The dominant logic: a new linkage between diversity and performance,' Strategic Management Journal, 7, 485-501.

Ravetz, J. R. (1971/1996), Scientific Knowledge and Its Social Problems. Transaction Publishers: New Brunswick, NJ.

Reber, A. S. (1989), Implicit Learning and Tacit Knowledge. An Essay on the Cognitive Unconscious. Oxford University Press: OxfordOxford Psychology Series No. 19.

Reber, A. S. (1991), 'Implicit and explicit learning: individual differences and IQ,' Journal of Experimental Psychology, 17, 888-896.

Reber, A. S. (1997), 'How to differentiate implicit and explicit modes of acquisition,' in J. D. Cohen and J. W. Schooler (eds), Scientific Approaches to Consciousness. Lawrence Erlbaum Associates: Mawah N.J.

Reed, R. and R. J. DeFillippi (1990), 'Causal ambiguity, barriers to imitation, and sustainable competitive advantage,' Academy of Management Review, 15, 88-102.

Resnick, L.B, R. Säljö, C. Pontecorvo and B. Burge (eds) (1991) Discourse, Tools and Reasoning. Essays in Situated Cognition. Springer: Berlin.

Rogers, C. F. C. (1983), The Nature of Engineering. A Philosophy of Technology. Macmillan: London.

Ryle, G. (1945/1946), 'Knowing how and knowing what,' Proceedings of the Aristotelian Society, 46, 1-16.

Sanchez, R. (1997), 'Managing articulated knowledge in competence-based competition,' in R. Sanchez and A. Heene (eds), Strategic Learning and Knowledge Management. Wiley: Chichester, pp. 163-187. 
Schooler, J. W. and T. Y. Engstler-Schooler (1990), 'Verbal overshadowing of visual memories: some things are better left unsaid,' Cognitive Psychology, 22, 36-71.

Schein, E. H. (1985), Organizational Culture and Leadership. Jossey-Bass: San Francisco.

Schön, D. A. (1983/1996), Reflective Practitioner - How Professionals Think in Action. Basic Books: New York.

Schulz, M. and L. A. Jobe (2001), 'Codification and tacitness as knowledge management strategies: an empirical exploration,' Journal of High Technology Management Research, 12, $139-165$.

Soo, C., T. Devinney, D. Midgley and A. Deering (2002), 'Knowledge management: philosophy, processes and pitfalls,' California Management Review, 44, 129-150.

Spender, J.-C. (1989), Industry Recipes. Oxford: Basil Blackwell.

Star, S. L. (1989), 'The structure of ill-structured solutions: boundary objects and heterogeneous distributed problem solving,' in M. Huhs and L. Gasser (eds), Readings in Distributed Artificial Intelligence 3. Morgan Kaufmann: Menlo Park, CA.

Sternberg, R. J. and J. A. Horvath, (eds) (1999), Tacit Knowledge in Professional Practice. Researcher and Practitioner Perspectives. Lawrence Erlbaum Associates: Mawah, NJ.

Subramaniam, M. and N. Venkatraman (2001), 'Determinants of transnational new product development capability: testing the influence of transferring and deploying tacit overseas knowledge,' Strategic Management Journal, 22, 359-378.

Teece, D. J. (1977), 'Technology transfer by multinational firms: the resource cost of transferring technological know-how,' Economic Journal, 87, 242-261.

Tononi, G. and G. Edelman (1998), 'Consciousness and complexity,' Science, 282, 1846-1851.

Tsoukas, H. and E. Vladimirou (2001), 'What is organizational knowledge?,' Journal of Management Studies, 38, 973-993.

Turnbull, D. (1993), 'The ad hoc collective work of building gothic cathedrals with templates, string and geometry,' Science, Technology, \& Human Values, 18, 315-340.

Vermeulen, R. C. M. (2002), 'Narrowing the transfer gap: The advantages of "as if" situations in training,' Journal of European Industrial Training, 26, 366-374.

Vincenti, W. G. (1990), What Engineers Know and How They Know It: Analytical Studies from Aeronautical History. Johns Hopkins University Press: Baltimore.

Wagner, R. and R. Sternberg (1985), 'Practical intelligence in real world pursuit: the role of tacit knowledge,' Journal of Personality and Social Psychology, 49, 436-458.

Watson, J. D. (1968), The Double Helix. Weidenfeld \& Nicolson: London.

Weick, K. E. (1995), Sensemaking in Organizations. Sage: Thousand Oaks, CA.

Weick, K. E. (1999), 'Sensemaking as an organizational dimension of global change,' in D. L. Cooperrider and J. E. Dutton (eds), Organizational Dimensions of Global Change. No Limits to Cooperation. Sage: Thousand Oaks, CA, pp. 39-56. 
Winter, S. G. (1987), 'Knowledge and competence as strategic assets,' in D. J. Teece (ed.), The Competitive Challenge - Strategies for Industrial Innovation and Renewal. Harper \& Row: New York, pp. 159-184.

Wright, R. W. (1997), 'Tangible integration versus intellectual codification skills: a comparison of learning processes in developing logic and memory semiconductors,' in R. Sanchez and A. Heene (eds), Strategic Learning and Knowledge Management. Wiley: Chichester, pp. 83-100.

Yates, J. (1989), Control Through Communication. The Rise of System in American Management. Johns Hopkins University Press: Baltimore.

Yates, J. (1990), 'For the record: the embodiment of organizational memory, 1850-1920,' Business and Economic History, 19, 172-182.

Zander, U. and B. Kogut (1995), 'Knowledge and the speed of transfer and imitation of organizational capabilities: an empirical test,' Organization Science, 6, 75-92.

Zollo, M. and S. G. Winter (2002), 'Deliberate learning and the evolution of dynamic capabilities,' Organization Science, 13, 339-351.

Zuboff, S. (1988), In the Age of the Smart Machine. Basic Books: New York. 